\title{
CORRELATION OF RADIOGRAPHIC DAMAGE AND METABOLIC SYNDROME IN SPONDYLOARTHRITIS: A CROSS-SECTIONAL STUDY
}

\author{
HENDRA GUNAWAN ${ }^{1 *}$, SONY WIBISONO MUDJANARKO ${ }^{2}$, AWALIA ${ }^{3}$, LITA DIAH RAHMAWATI ${ }^{3}$, \\ JOEWONO SOEROSO ${ }^{3}$, AGUNG PRANOTO ${ }^{2}$
}

${ }^{1}$ Department of Residence of Internal Medicine, Dr. Soetomo General Hospital Surabaya - Airlangga University, Indonesia. ${ }^{2}$ Department of Internal Medicine - Endocrinology, Metabolic, and Diabetes Division, Dr. Soetomo General Hospital, Surabaya, Indonesia - Airlangga University, Indonesia. ${ }^{3}$ Department of Internal Medicine - Rheumatology Division, Dr. Soetomo General Hospital, Surabaya, Indonesia Airlangga University, Indonesia. Email: Sylvester.gunawan@gmail.com/Awalia_nov74@yahoo.com

Received: 08 August 2019, Revised and Accepted: 08 August 2019

ABSTRACT

Background: Cardiovascular complication remains the long-term complications in spondyloarthritis (SpA). Previous studies revealed that metabolic syndrome is the risk factor of cardiovascular in SpA patients. Previous studies also revealed that the prevalence of the metabolic syndrome is 34.9$45.7 \%$ in SpA patients. However, previous studies also revealed the controversy of the correlation of SpA' disease activity with metabolic syndrome.

Aim: The aim of the study was to investigate the correlation of SpA' radiographical damage measured with a modified Stoke Ankylosing Spondylitis Spinal Score (mSASSS) score with metabolic syndrome in SpA patients, which routinely visited Rheumatology Outpatient Department in Dr. Soetomo General Hospital.

Methods: An observational study with cross-sectional design with consecutive sampling technique was conducted in July-0ctober 2018. All SpA patients who fulfilled the inclusion criteria were included in this study. Data analysis was performed with SPSS v21.0.

Results: There were $33 \mathrm{SpA}$ patients (10 males and 23 females) included in this study. The average age was $48.18 \pm 12.27$ years-old. The average mSASSS score was 24,36 (K:0.93, p:0.00). Metabolic syndrome was diagnosed in 54.5\% patients with 100\% patients had central obesity, $66.7 \%$ had increased blood pressure, $61.5 \%$ had impaired fasting glucose, $55.6 \%$ had increased triglycerides, and $77.8 \%$ had decreased high-density lipoprotein cholesterol. Positive correlation between mSASSS score and metabolic syndrome was observed (r:0.510, p:0.002).

Conclusion: A correlation between SpA disease activity measured with mSASSS score and metabolic syndrome was observed. Therefore, routine metabolic syndrome screening is strongly suggested for SpA patients.

Keywords: Metabolic syndrome, Spondyloarthritis, Modified stoke ankylosing spondylitis spinal score.

(c) 2019 The Authors. Published by Innovare Academic Sciences Pvt Ltd. This is an open access article under the CC BY license (http://creativecommons. org/licenses/by/4. 0/) DOI: http://dx.doi.org/10.22159/ijap.2019.v11s5.T0049

\section{BACKGROUND}

Spondyloarthritis $(\mathrm{SpA})$ is a chronic inflammatory disorder which is related to the presence of HLA-B27. SpA has various clinical symptoms ranging from chronic inflammatory back pain, peripheral arthritis, to enteropathy arthritis, and uveitis [1,2]. Among its longterm complication, cardiovascular complications remain the leading morbidity and mortality in SpA patients. Previous studies revealed that cardiovascular complications risk such as myocardial infarction and cerebrovascular accident are accelerated in SpA population [3,4].

One of the cardiovascular risk factors is metabolic syndrome. It is a constellation of obesity, insulin resistance, hypertension, and dyslipidemia [5]. Mottillo et al. revealed that metabolic syndrome increases the risk of cardiovascular complications at least two-fold and all-cause mortality by at least 1.5 -fold. Previous studies also revealed that the prevalence of the metabolic syndrome is increased in SpA patients, ranging from $34.9 \%$ to $45.7 \%[6,7]$. Interestingly, current understandings of metabolic syndrome have suggested that metabolic syndrome is associated with chronic low-grade inflammation [8]. The mechanism remains uncertain, but it involves proinflammatory cytokines such as tumor necrosis factor- $\alpha$ (TNF- $\alpha$ ) and interleukin (IL)- 6 which contributes to the insulin resistance, central obesity, dyslipidemia, and hypertension $[8,9]$.

Despite the increased prevalence in rheumatic diseases, few studies have reported the correlation of SpA' disease activity and functional score to metabolic syndrome with various outcomes [6,7,10-12]. However, as SpA' disease activity score such as bath-AS ankylosing spondylitis disease activity index (BASDAI) is dependent to subject's psychological and functional state, it may not reflect the severity of SpA $[13,14]$. Radiographic assessment can be used to assess the severity of SpA using modified Stoke Ankylosing Spondylitis Spinal Score (mSASSS) [15]. Furthermore, assessing radiographic damage can evaluate therapy response, the progression of the disease, and associated with magnetic resonance imaging [16]. This study aimed to investigate the correlation of radiographic damage, measured with mSASSS score with metabolic syndrome in SpA patients.

\section{METHODS}

This study is a cross-sectional study conducted from July 2018 to October 2018 in Rheumatology Outpatient installation Dr. Soetomo General Hospital Surabaya, an A class hospital with consecutive sampling technique to recruit the subject. This study has been approved by the Ethics Committee of Dr. Soetomo General Hospital on July 10, 2018, with reference number: 0385/KEPK/VII/2018.

\section{Study population}

Consecutive patients $(\mathrm{n}=33 ; 10$ males and 23 females; mean age $48.18 \pm 12.27$ years) attending the Rheumatology Outpatient Department of Dr. Soetomo General Hospital Surabaya between July 2018 and September 2018, were enrolled in the study. All patients fulfilled the ASAS 2010 criteria for SpA [1]. The exclusion criteria in 
this study are smoking, previous alcohol consumption, chronic kidney disease, previous medications (glucocorticoid and anti-TNF $\alpha$ ), history of malignancy, infection (HIV and hepatitis), and other autoimmune diseases. The median of disease duration was 4 years ( $0-43$ years) and six patients were diagnosed with $\mathrm{SpA}$ at the time of the recruitment. Nineteen patients were taking sulfasalazine with median dose $1000 \mathrm{mg} /$ day (500-2000 mg/day) and eight patients were taking methotrexate with median dose $10 \mathrm{mg} /$ week (7.5-10 mg/weekly). Fourteen patients were taking Anti-hypertensive drugs (angiotensinconverting enzyme inhibitor, Angiotensin receptor blocker, calcium channel blocker, $\beta$-blocker, or combination therapy), 19 patients were taking dyslipidemia drugs (statins or fibrates), and four patients were taking oral hypoglycemic agents (biguanides).

\section{mSASSS score}

Radiography assessment was measured using mSASSS score. There are two components which are evaluated in mSASSS score, the anterior vertebrae which consist of the lower border of $\mathrm{C} 2$ to the upper border of Th1 and the lumbar vertebrae which consist of the lower border of Th12 to the upper border of S1 combined to 24 vertebrae segments at a lateral view. The vertebrae segments were evaluated for the presence of erosion and/or sclerosis and/or squaring (1 point), syndesmophyte ( 2 points), and bridging syndesmophytes (three points). The total score ranges from 0 to 72 [15]. The radiology assessment was performed by two rheumatologists (Awalia and Lita Diah) who were blinded to demographic and clinical manifestations. Both readers scored the radiography assessment at the same time and registered the changes of vertebrae segments separately; therefore, both scores could be computed.

\section{Metabolic syndrome}

Metabolic syndrome was assessed with National Cholesterol Education Program-Adult Treatment Panel (NCEP)-ATP III criteria. According to NCEP-ATP III, metabolic syndrome is defined as the presence of minimal three of the following five risk factors such as (1) central obesity, (2) elevated triglycerides $(>150 \mathrm{mg} / \mathrm{dL}$ ) or previous dyslipidemia medication, (3) fasting glucose $>100 \mathrm{mg} / \mathrm{dL}$ or previous diabetes medication, (4) blood pressure $>130 / 80 \mathrm{mmHg}$, and (5) high-density lipoprotein (HDL) $<40 \mathrm{mg} / \mathrm{dL}$ for male and $<50 \mathrm{mg} / \mathrm{dL}$ for female [17]. As for central obesity, we used the modified criteria of central obesity based on waist circumference $>90 \mathrm{~cm}$ for male and $>80 \mathrm{~cm}$ for female or body mass index for Indonesian populations which defines overweight at $23.0-24.9 \mathrm{~kg} / \mathrm{m}^{2}$, obese I at $25.0-29.9 \mathrm{~kg} / \mathrm{m}^{2}$, and obese II at $\geq 30 \mathrm{~kg} / \mathrm{m}^{2}[18,19]$.

\section{Statistical analysis}

The statistical analysis was made by SPSS v21.0 software for MacOSX. Interobserver analysis of mSASSS score to validate the mSASSS score was performed with Cohen-Kappa analysis. Shapiro-Wilk test was used to test the normality of the mSASSS score, followed with Mann-Whitney U-test for mean differences of mSASSS score based on the presence of the metabolic syndrome. Spearman's rank correlation was used for correlation analysis between mSASSS score and metabolic syndrome and the number of metabolic syndrome component.

\section{RESULTS}

\section{Demography}

There were $33 \mathrm{SpA}$ patients who visited the rheumatology outpatient department from July to October 2018 consisted of 23 females and 10 males. There were 6 (18.1\%) newly diagnosed SpA patients; therefore, 27 patients had a history of conventional synthetic diseasemodifying anti-rheumatic drug (csDMARDs), with 8 patients $(24.2 \%)$ on methotrexate, and 19 patients $(57.6 \%)$ on sulfasalazine. No patients had a history of metabolic syndrome before diagnosed with SpA, smoking, alcohol consumption, chronic kidney disease, or anti-TNF $\alpha$ medication. Table 1 shows the basic characteristics of the subjects.

Prevalence of metabolic syndrome components in SpA patients Fig 1 shows the prevalence of each component of metabolic syndrome in $\mathrm{SpA}$ patients. Central obesity was the most frequent metabolic
Table 1: Basic characteristics of the study

\begin{tabular}{ll}
\hline Parameter & Value \\
\hline Age (years) & $50(22-72)$ \\
Waist circumference $(\mathrm{cm})$ & $88(68-108)$ \\
Body Mass Index $\left(\mathrm{kg} / \mathrm{m}^{2}\right)$ & $26.45(17.48-36.07)$ \\
Blood pressure & \\
$\quad$ Systolic $(\mathrm{mmHg})$ & $120(100-170)$ \\
$\quad$ Diastolic $(\mathrm{mmHg})$ & $80(70-90)$ \\
Hemoglobin $(\mathrm{g} / \mathrm{dL})$ & $12.7(9.3-15.9)$ \\
Leukocytes $(\mu / \mathrm{L})$ & $7910(3490-14450)$ \\
Platelets $(\mu / \mathrm{L})$ & $326,000(206,000-555,000)$ \\
Fasting glucose concentration & $97(78-284)$ \\
(mg/dL) & $194(115-255)$ \\
Total cholesterol (mg/dL) & $115(45-372)$ \\
Triglycerides $(\mathrm{mg} / \mathrm{dL})$ & $47(31-99)$ \\
HDL-cholesterol $(\mathrm{mg} / \mathrm{dL})$ & $118(46-157)$ \\
LDL-cholesterol $(\mathrm{mg} / \mathrm{dL})$ & $4(1-43)$ \\
Duration of disease $(\mathrm{years})$ & $23(9-60)$ \\
mSASSS score & $14(42)$ \\
On anti-hypertensive $(\%)$ & $14(42)$ \\
On statins $(\%)$ & $4(12)$ \\
On oral antidiabetic drugs $(\%)$ &
\end{tabular}

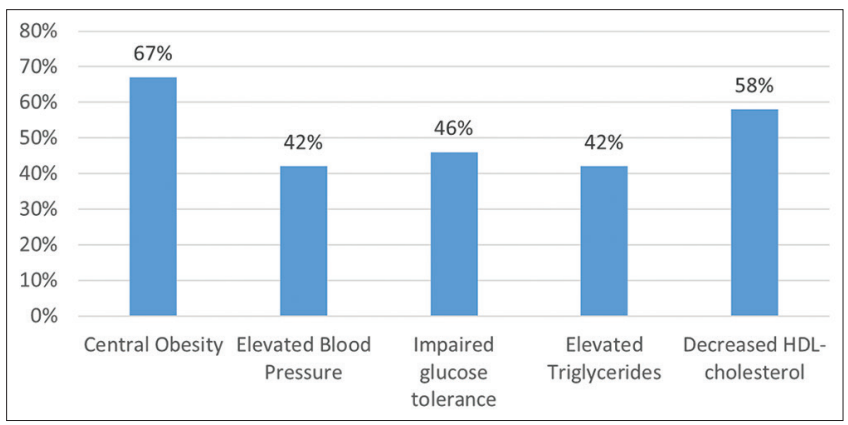

Fig. 1: Prevalence of the metabolic syndrome components in spondyloarthritis patients

syndrome component found in this study with a prevalence of $67 \%$, followed with decreased HDL-cholesterol and impaired glucose tolerance. When we classified the patients with central obesity according to their body mass index (BMI) for Indonesian populations, we found that $92 \%$ met the obese criteria (10 with obese I and 10 with obese II) and 8\% (two patients) met the overweight criteria.

About 42\% (14 patients) of the patients met the criteria of elevated blood pressure or had an antihypertensive drugs history before. When we classified patients with elevated blood pressure according to their blood pressure with JNC VII criteria, we found that $42 \%$ (6 out of 14) met the criteria of hypertension Stage I, 29\% (4 out of 14) met the criteria of hypertension Stage II, and 29\% (4 out of 14) had a normal blood pressure.

The prevalence of impaired glucose tolerance was $46 \%$ (15 patients) in this study, with $27 \%$ (4 out of 15 ) had already been diagnosed with type 2 diabetes mellitus. All patients with diabetes received oral antidiabetic drugs (biguanides)

The prevalence of elevated triglycerides was $42 \%$ (14 patients) in this study. All patients with elevated triglycerides were on statins. When we classified the patients according to their triglycerides level with NCEP-ATP III classification, we found that $43 \%$ ( 6 out of 14 ) were on borderline-high triglycerides (150-199 mg/dL), 43\% (6 out of 14) were on high triglycerides (200-499 mg/dL), and 14\% (2 out of 14) were on normal triglycerides level.

The prevalence of decreased HDL-cholesterol was 58\% (19 patients) in this study with $73.7 \%$ (14 out of 19 ) were on statins. When we classified the patients according to their HDL-cholesterol level with NCEP-ATP 
III classification, we found that $47 \%$ (9 out of 19) were on low level $(<40 \mathrm{mg} / \mathrm{dL}$ ), 47\% (9 out of 19 ) were on normal level, and $6 \%$ (1 out of 19) were on a high level of HDL-cholesterol (>60 mg/dL).

\section{Prevalence of metabolic syndrome in SpA patients}

The prevalence of metabolic syndrome in this study was $54.5 \%$ (18 out of 33 patients) according to the NCEP-ATP III classification of metabolic syndrome modified for Indonesian populations. When we split the patients based on metabolic syndrome diagnosis, we found that $44.4 \%$ (8 out of 18 ) had three components of metabolic syndrome, $38.9 \%$ (7 out of 18) had four components of metabolic syndrome, and $16.7 \%$ ( 3 out of 18) had five components of metabolic syndrome as shown in Fig. 2.

Table 2 describes the metabolic syndrome parameters in SpA patients according to the presence of the metabolic syndrome. When we classified the patients according to the presence of metabolic syndrome, we found that patients with metabolic syndrome were significantly older $(\mathrm{p}=0.003)$ and had a longer duration of diseases $(p=0.000)$. All patients with metabolic syndrome had central obesity $(100 \%)$, had a significantly greater waist circumference $(p=0.002)$, and BMI $(p=0.000)$ compared with patients without metabolic syndrome.

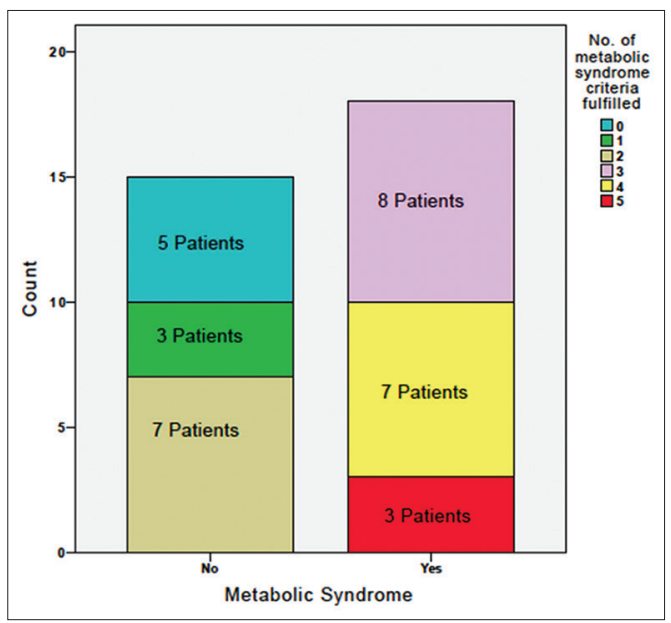

Fig. 2: The distribution of metabolic syndrome components according to metabolic syndrome
Elevated blood pressure was observed in 66.67\% (12) patients with metabolic syndrome; however, there were no significant differences in systolic and diastolic blood pressure in patients with and without metabolic syndrome ( $\mathrm{p}=0.213$ and $\mathrm{p}=0.185$, respectively).

Impaired glucose tolerance was more prevalent in patients with metabolic syndrome (61.5\%) compared to those without metabolic syndrome (13.3\%). When we compared the fasting glucose concentration, we found a higher glucose concentration in patients with metabolic syndrome than those without metabolic syndrome $(p=0.000)$.

Increased triglycerides were observed in $61.5 \%$ (11) patients with metabolic syndrome, compared to $26.7 \%$ (4) in patients without metabolic syndrome. There were no significant differences in triglycerides level in patients with and without metabolic syndrome $(p=0.093)$. Similarly, the prevalence of decreased HDL-cholesterol was higher in patients with metabolic syndrome $(77.8 \%)$ compared to patients without metabolic syndrome $(33.3 \%)$. There were no differences in HDL-cholesterol levels in patients with or without metabolic syndrome $(\mathrm{p}=0.128)$

\section{mSASSS score}

The median score of mSASSS score in this study was 23, as shown in Table 1 with interobserver agreement calculated with CohenKappa's method $\kappa=0.93, p=0.00$. When we compared the mSASSS score according to the presence of metabolic syndrome, we found that patients with metabolic syndrome had higher mSASSS score compared to those without metabolic syndrome $(\mathrm{p}=0.004)$.

\section{Correlation of mSASSS score and metabolic syndrome in SpA patients}

Correlation of mSASSS score and metabolic syndrome was calculated with Spearman correlations. We found a moderate correlation between mSASSS score and metabolic syndrome $(p=0.510, p=0.002)$. We also found a weak correlation between mSASSS core and the number of metabolic syndrome components $(\mathrm{p}=0.448, \mathrm{p}=0.009)$

\section{DISCUSSION}

SpA is a chronic inflammatory disease with various clinical manifestations, ranging from ankylosing spondylitis to undifferentiated arthritis. It affects male predominantly with male: female ratio 2-3:1 [20]. However, female was more predominant in this study, accounts for $67 \%$ subjects in this study with an average age 48 years old. This supports the previous study which reported that the male: female ratio

Table 2: Characteristic of spondyloarthritis patients according to the presence of the metabolic syndrome

\begin{tabular}{|c|c|c|c|}
\hline \multirow[t]{2}{*}{ Parameter } & \multicolumn{2}{|l|}{ Metabolic syndrome } & \multirow[t]{2}{*}{$\mathbf{p}$} \\
\hline & Yes $(n=18)$ & No $(n=15)$ & \\
\hline \multicolumn{4}{|l|}{ Sex } \\
\hline Male (\%) & $4(22.2)$ & $6(40)$ & $0.003^{*}$ \\
\hline Female (\%) & $14(77.8)$ & $9(60)$ & \\
\hline Age (years) & $52(39-72)$ & $44(22-63)$ & \\
\hline Central obesity (\%) & $18(100)$ & $4(26.7)$ & $0.002^{*}$ \\
\hline Waist circumference $(\mathrm{cm})$ & $91.5(82-108)$ & $77(68-106)$ & $0.000^{*}$ \\
\hline Body mass index $\left(\mathrm{kg} / \mathrm{m}^{2}\right)$ & $30.06(23.63-36.07)$ & $21.63(17.48-31.25)$ & \\
\hline Elevated blood pressure (\%) & $12(66.67)$ & $2(13.3)$ & 0.213 \\
\hline Systolic $(\mathrm{mmHg})$ & $135(100-170)$ & $120(110-160)$ & 0.185 \\
\hline Diastolic (mmHg) & $80(70-90)$ & $80(70-90)$ & \\
\hline Impaired glucose tolerance (\%) & $11(61.5)$ & $2(13.3)$ & $0.001^{*}$ \\
\hline Fasting glucose concentration $(\mathrm{mg} / \mathrm{dL})$ & $103(86-284)$ & $93(78-103)$ & \\
\hline Increased triglycerides (\%) & $10(55.6)$ & $4(26.7)$ & 0.093 \\
\hline Triglycerides (mg/dL) & $142.5(60-372)$ & $104(45-203)$ & \\
\hline Duration of disease (years) & $7.5(1-43)$ & $2.25(1.25-7.25)$ & $0.000^{*}$ \\
\hline mSASSS score & $26(18-60)$ & $20(9-29)$ & $0.004^{*}$ \\
\hline
\end{tabular}

*Significant with Mann-Whitney U-test analysis $(\mathrm{p}<0.05)$. mSASSS: Modified stoke ankylosing spondylitis spinal score 
is equal in older populations (45 years old) and female was associated with lower quality of life and more functional limitations despite lower degrees of radiographical damage [21,22]. The reason female was predominant in this study because our study location is referral hospital. Thereby, our cases were difficult cases which is commonly found in female with as (Skare et al, 2012).

The prevalence of metabolic syndrome in this study was $54.5 \%$, which was higher compared to the prevalence of metabolic syndrome in a healthy population that visited primary health care in Jakarta, which was $28.4 \%$ [23]. This finding supports previous studies which reported that the prevalence of metabolic syndrome in SpA populations is higher than the healthy population $[3,24]$ Compared to other studies, Malesci et al. reported that the prevalence of metabolic syndrome in SpA patients in Italy was $45.8 \%$ [6]. Maia et al., which observed metabolic syndrome in Brazilian ankylosing spondylitis patients and Papadakis et al., which observed metabolic syndrome in male Greek ankylosing spondylitis patients reported that the prevalence of metabolic syndrome was $27 \%$ and $34.9 \%$, respectively $[7,11]$. The differences between this study and previous studies might be due to treatment differences because all of the patients in this study received csDMARDs which did not affect metabolic syndrome's parameters directly like anti-TNF $\alpha$ which was used in some of the previous studies [25].

Analyzing the component of metabolic syndrome, central obesity was the most common metabolic syndrome's component found in this study, followed by decreased HDL-cholesterol and impaired glucose tolerance. These findings are different from previous studies since elevated blood pressure was the more prevalent metabolic syndrome's component. This might be due to the predominant gender differences in our study in which female was the more predominant, with average age 48 years, and $69.6 \%$ of the female were in the menopause period. Menopause is associated with hyperandrogenemia which associated with insulin resistance and abdominal fat disposition [26].

When we analyzed the patients according to the presence of metabolic syndrome, we found that central obesity was still the most prevalent metabolic syndrome component in $\mathrm{SpA}$ patients with metabolic syndrome followed by decreased HDL-cholesterol, elevated blood pressure, and impaired glucose tolerance. These findings support previous studies which reported that $\mathrm{SpA}$ patients with metabolic syndrome were older and had more cardiovascular comorbidities than those who did not have metabolic syndrome $[7,11]$. Because all patients in this study were not on anti-TNF $\alpha$, we thought that chronic inflammation due to TNF- $\alpha$ activation might have a part in the adverse metabolic parameter in this study $[9,24]$.

To the best of our knowledge, this is the first study which observed the mSASSS score in Indonesian population. The average mSASSS score in this study was higher than the previous studies indicated that there was more radiographical damage in our patients $[15,27]$. This might due to the nature of $\mathrm{SpA}$, which is chronic progressive and patient's characteristics in this study. All patients in this study were referral cases, so the possibility of late referral cases needed to be accounted [28]. When we analyzed the mSASSS score based on metabolic syndrome, we found that the average mSASSS score in patients with metabolic syndrome was significantly higher than those who did not have metabolic syndrome. This finding is the first one who observed mSASSS score in patients with metabolic syndrome. This supports the hypothesis that inflammation in the enthesis would increase the activation of IL-17, which further activates the IL-23/IL-17 axis [29]. Golden et al. reported that activation of IL-23/IL-17 axis in enthesis would not only affect local inflammation but also associated with extra-articular complications of SpA [30].

This is the first study which observed the positive correlation of mSASSS score and metabolic syndrome and number of metabolic syndrome components in SpA patients. These findings supported the findings of Papadakis et al., in male Greek ankylosing spondylitis patients and Alonso-Blanco Morales et al., in Spanish ankylosing spondylitis patients $[7,10]$. However, previous studies used other methods such as BASDAI and BASFI in which both methods evaluate disease activity from the patient's perception of their disease $[31,32]$. Thus, we thought that the severity of inflammation evaluated with mSASSS score was more objective to evaluate the duration of long-term inflammation in $\mathrm{SpA}$; however, further studies are needed to evaluate the relationships between mSASSS score and long-term complication of SpA.

This study has some limitations. We analyzed small numbers of patients with cross-sectional design in relatively limited time; therefore, the cause-effect relationships between chronic inflammation in SpA and metabolic syndrome could not be determined. The location of this study is in A class hospital; therefore, all patients were referral cases, and it could affect the higher mSASSS score in this study.

\section{CONCLUSION}

Our findings showed that the greater prevalence of metabolic syndrome in chronic inflammatory diseases, in this case, was SpA. The correlation of radiographical damage evaluated by mSASSS score with metabolic syndrome and number of metabolic syndrome components suggested the role of inflammation to the pathogenesis of metabolic syndrome in SpA patients. Early diagnosis and treatment of metabolic syndrome in SpA patients are needed to prevent cardiovascular complications.

\section{ACKNOWLEDGMENT}

We acknowledge Poernomo Boedi Setiawan, dr. Sp.PD-KGEH as the head of Internal Medicine Department of Airlangga University for giving us permission to manage and write this case report. We also acknowledge all staffs in Internal Medicine Department for the support given to us.

\section{CONFLICTS OF INTEREST}

The authors declare that there are no conflicts of interest regarding the publication of this article.

\section{REFERENCES}

1. Rudwaleit M, van der Heijde D, Landewé R, Akkoc N, Brandt J, Chou CT, et al. The assessment of spondyloarthritis international society classification criteria for peripheral spondyloarthritis and for spondyloarthritis in general. Ann Rheum Dis 2011;70:25-31.

2. Zochling J, Brandt J, Braun J. The current concept of spondyloarthritis with special emphasis on undifferentiated spondyloarthritis. Rheumatology (Oxford) 2005;44:1483-91.

3. Mathieu S, Gossec L, Dougados M, Soubrier M. Cardiovascular profile in ankylosing spondylitis: A systematic review and meta-analysis. Arthritis Care Res (Hoboken) 2011;63:557-63.

4. Mathieu S, Pereira B, Soubrier M. Cardiovascular events in ankylosing spondylitis: An updated meta-analysis. Semin Arthritis Rheum 2015;44:551-5.

5. Reaven G. The metabolic syndrome: Is this diagnosis necessary? Am J Clin Nutr 2006;83:1237-47.

6. Malesci D, Niglio A, Mennillo GA, Buono R, Valentini G, La Montagna $\mathrm{G}$, et al. High prevalence of metabolic syndrome in patients with ankylosing spondylitis. Clin Rheumatol 2007;26:710-4.

7. Papadakis JA, Sidiropoulos PI, Karvounaris SA, Vrentzos GE, Spanakis EK, Ganotakis ES, et al. High prevalence of metabolic syndrome and cardiovascular risk factors in men with ankylosing spondylitis on anti-TNFalpha treatment: Correlation with disease activity. Clin Exp Rheumatol 2009;27:292-8.

8. Monteiro R, Azevedo I. Chronic inflammation in obesity and the metabolic syndrome. Mediators Inflamm 2010;2010:???.

9. Jung UJ, Choi MS. Obesity and its metabolic complications: The role of adipokines and the relationship between obesity, inflammation, insulin resistance, dyslipidemia and nonalcoholic fatty liver disease. Int J Mol Sci 2014; 15:6184-223.

10. Blanco-Morales EA, Bravo-Ferrer J, Rey R, Bejerano C, Fernandez C, Oreiro N, et al. FRI0208 metabolic syndrome in spondyloarthritis. Prevalence and associated factors. Ann Rheumatic Dis 2015;2015:499-500.

11. Maia DG, Augusto KL, Bezerra MC, Rodrigues CEM. Metabolic 
syndrome in patients with ankylosing spondylitis receiving anti-TNF $\alpha$ therapy: Association with predictors of cardiovascular risk. Clin Rheumatol 2017;36:2371-6.

12. Betancur G, Orozco MC, Schneeberger E, Lizarraga A, Zamora N, Sommerfleck FA, et al. Prevalence of obesity and metabolic syndrome in patients with axial spondyloarthritis. Arthritis Rheumatol 2015;67 Suppl 10.

13. Altan L, Sivrioglu Y, Ercan I. Can bath ankylosing spondylitis disease activity index be affected by accompanying fibromyalgia or depression? Arch Rheumatol 2015;30:34-9.

14. Pedersen SJ, Sørensen IJ, Garnero P, Johansen JS, Madsen OR, Tvede $\mathrm{N}$, et al. ASDAS, BASDAI and different treatment responses and their relation to biomarkers of inflammation, cartilage and bone turnover in patients with axial spondyloarthritis treated with TNF $\alpha$ inhibitors. Ann Rheum Dis 2011;70:1375-81.

15. Creemers MC, Franssen MJ, van't Hof MA, Gribnau FW, van de Putte LB, van Riel PL, et al. Assessment of outcome in ankylosing spondylitis: An extended radiographic scoring system. Ann Rheum Dis 2005;64:127-9.

16. Ibrahim A, Gladman DD, Thavaneswaran A, Eder L, Helliwell P, Cook RJ, et al. Sensitivity and specificity of radiographic scoring instruments for detecting change in axial psoriatic arthritis. Arthritis Care Res (Hoboken) 2017;69:1700-5.

17. National cholesterol education program. Detection, evaluation, and treatment of high blood cholesterol in adults (adult treatment panel III). Circulation 2001;2002:3143-421.

18. Tan CE, Ma S, Wai D, Chew SK, Tai ES. Can we apply the national cholesterol education program adult treatment panel definition of the metabolic syndrome to asians? Diabetes Care 2004;27:1182-6.

19. Tjokroprawiro A, Wibisono S. Guloh-sisar: Sepuluh Petunjuk Pola Hidup Sehat. Seminar Untuk Dokter Anak Cabang Jawa Timur. Vol. 29. Surabaya: Practical Guidelines fro Healthy Daily Life; 2014.

20. Harper BE, Reveille JD. Spondyloarthritis: Clinical suspicion, diagnosis, and sports. Curr Sports Med Rep 2009;8:29-34

21. Haroon NN, Paterson JM, Li P, Haroon N. Increasing proportion of female patients with ankylosing spondylitis: A population-based study of trends in the incidence and prevalence of AS. BMJ Open 2014;4:e006634.

22. Neuenschwander R, Ciurea A. Gender differences in axial spondyloarthritis. World J Rheumatol 2014;4:35-43.

23. Soewondo P, Purnamasari D, Oemardi M, Waspadji S, Soegondo S. Prevalence of metabolic syndrome using NCEP/ATP III criteria in jakarta, indonesia: The jakarta primary non-communicable disease risk factors surveillance 2006. Acta Med Indones 2010;42:199-203.

24. Papagoras C, Markatseli TE, Saougou I, Alamanos Y, Zikou AK, Voulgari PV, et al. Cardiovascular risk profile in patients with spondyloarthritis. Joint Bone Spine 2014;81:57-63.

25. Owczarczyk-Saczonek A, Drozdowski M, Maciejewska-Radomska A, Choszcz D, Placek W. The effect of subcutaneous methotrexate on markers of metabolic syndrome in psoriatic patients preliminary report. Postepy Dermatol Alergol 2018;35:53-9.

26. Kozakowski J, Gietka-Czernel M, Leszczyńska D, Majos A. Obesity in menopause our negligence or an unfortunate inevitability? Prz Menopauzalny 2017; 16:61-5

27. Ramiro S, van Tubergen A, Stolwijk C, Landewé R, van de Bosch F, Dougados $\mathrm{M}$, et al. Scoring radiographic progression in ankylosing spondylitis: Should we use the modified stoke ankylosing spondylitis spine score (mSASSS) or the radiographic ankylosing spondylitis spinal score (RASSS)? Arthritis Res Ther 2013;15:R14.

28. Braun J, Pincus T. Mortality, course of disease and prognosis of patients with ankylosing spondylitis. Clin Exp Rheumatol 2002;20:S16-22.

29. Raychaudhuri SP, Raychaudhuri SK. IL-23/IL-17 axis in spondyloarthritis-bench to bedside. Clin Rheumatol 2016;35:1437-41.

30. Golden JB, McCormick TS, Ward NL. IL-17 in psoriasis: Implications for therapy and cardiovascular co-morbidities. Cytokine 2013;62:195-201.

31. Aliling $\mathrm{J}$, Brent $\mathrm{lH}$. Criteria and disease activity measures in axial spondyloarthropathies. Clin Adv Spondylitis 2016;2:2-38.

32. Braun J, Kiltz U, Baraliakos X, van der Heijde D. Optimisation of rheumatology assessments the actual situation in axial spondyloarthritis including ankylosing spondylitis. Clin Exp Rheumatol 2014;32:S96-104. 